\title{
Correction to: Joint report on terminology for surgical procedures to treat pelvic organ prolapse
}

\author{
Developed by the Joint Writing Group of the American Urogynecologic Society \\ and the International Urogynecological Association
}

Published online: 8 May 2020

(C) The International Urogynecological Association 2020

\section{Correction to: International Urogynecology Journal (2020) 31:429-463 https://doi.org/10.1007/s00192-020-04236-1}

In the AUGS-IUGA joint publication, "Joint Report on Terminology for Surgical Procedures to Treat Pelvic Organ Prolapse," [1] appearing on pages 429-463 of the March 2020 issue of International Urogynecology Journal (volume 31, issue 3), there is an error with the figure legends pertaining to Fig. 3 and Fig. 4 . The correct figure legend for Fig. 3, on page 439, should be "Uterosacral ligament suspension using the midline plication technique variation" and the correct figure legend for Fig. 4, on page 440, should be "Uterosacral ligament suspension using the ipsilateral technique variation." The callouts for these respective figures are also incorrect. On page 438, the correct callout for Fig. 4 should be under the "List of Steps" heading and read, "Step 2: The USLs are identified. In the ipsilateral USLS technique
(Fig. 4), sutures are placed...” On page 438, the correct callout for Fig. 3 should be under the "Technique Variations" heading and read, "In another common variation, the USLs are plicated across the midline using sutures (Fig. 3)."

\section{Reference}

1. Developed by the Joint Writing Group of the American Urogynecologic Society and the International Urogynecological Association. Joint report on terminology for surgical procedures to treat pelvic organ prolapse. Int Urogynecol J. (2020) 31:429-463.

Publisher's note Springer Nature remains neutral with regard to jurisdictional claims in published maps and institutional affiliations.
The online version of the original article can be found at https://doi.org/ 10.1007/s00192-020-04236-1

Correspondence: Kate V. Meriwether, University of New Mexico Hospital, 2211 Lomas Blvd NE, 4th Flr, Department of Obstetrics \& Gynecology, Albuquerque, NM 87106, USA.

E-mail: meriwet2@salud.unm.edu. 